\title{
Variable genomic patterns of hybridization in an expanding hybrid zone of damselflies
}

\author{
Rosa Ana Sánchez-Guillén ${ }^{1}$, Luis Rodrigo Arce-Valdés ${ }^{2}$, Janne Swaegers ${ }^{3}$, Pallavi \\ Chauhan $^{4}$, Jesús Cávez-Rios ${ }^{5}$, Anais Rivas-Torres ${ }^{6}$, Maren Wellenreuther ${ }^{7}$, and Bengt \\ Hansson $^{4}$ \\ ${ }^{1}$ Instituto de Ecología A. C., Xalapa 91070, Veracruz \\ ${ }^{2}$ INECOL \\ ${ }^{3}$ Affiliation not available \\ ${ }^{4}$ Lund University \\ ${ }^{5}$ Universidad Nacional Autonoma de Mexico Instituto de Investigaciones Biomedicas \\ ${ }^{6} \mathrm{MARE}$ \\ ${ }^{7}$ The University of Auckland
}

March 3, 2022

\begin{abstract}
The outcome of hybridization is of major interest in evolutionary and conservation biology. Here, we investigate (i) the genomic signal of the hybridization dynamics, (ii) the strength of reproductive barriers preventing copulation in heterospecific and hybrid crosses, and (iii) the population dynamics (stability of species proportions) of the two damselfly species Ischnura elegans and I. graellsii in two differently aged Spanish hybrid regions. RAD sequencing in these hybrid regions and in allopatric populations was used to generate 5,702 SNPs to quantify population diversity and population differentiation, and a subset of 381 speciesspecific SNPs to analyze individual ancestry and the proportion of individuals in different hybrid classes. Our individual ancestry results showed the presence of F1 and F2 hybrids, in line with on-going hybridization and bidirectional backcrossing in both hybrid regions, with almost complete absence of genetically pure I. elegans and I. graellsii. Different admixture-class distributions were in part explained by 1) different mean strength of reproductive barriers in the hybrid regions, with stronger barrier in the older hybrid region, 2) local dynamics (continuous recolonization events), 3) proximity to introduction site, and 4) time elapsed since colonization. Consistent with theoretical expectations, introgression maintained (in the younger hybrid region) or increased genetic diversity (in the older hybrid region), and reduced genetic differentiation between local populations in both hybrid regions. Whether this will facilitate the ongoing range expansion of I. elegans in Spain is an interesting avenue for future research.
\end{abstract}

\section{INTRODUCTION}

In recent years, many insect species have experienced pronounced changes in their distribution, including several documented cases of range expansions (González-Tokman et al., 2020; Sánchez-Guillén et al., 2016). A common signature of range expansion is decreasing genetic diversity at the range limit, due to frequent founder effects and genetic drift (Slatkin \& Excoffier, 2012). However, such a loss of diversity can be counteracted by hybridization and introgression in situations where the expanding species comes in contact with a formerly allopatric sister taxa (Rieseberg et al., 2007). This process is of increasing interest as many regions are facing changes due to anthropogenic pressures and ongoing climate change, which can lead to novel interactions and hybridization among expanding species (Sánchez-Guillén et al., 2016). Evidence is accumulating that both the extent and pattern of hybridization have important conservation implications 
due to their direct impact on biodiversity as a whole, and because this process can sometimes lead to the replacement of one of the hybridizing taxa (Abbott et al., 2013; Seehausen, 2004; Todesco et al., 2016). Thus, understanding evolutionary outcomes of hybridization is of increasing interest for gaining general insights into species dynamics and conservation in response to environmental change (Abbott et al., 2013).

Hybridization outcomes are manifold and include transfer of genetic material between species (potentially facilitating their adaptive evolution), fusion of species, genetic swamping of one species by another, elicit reinforcement of reproductive isolation between incompletely isolated species, and the origin of new species (Seehausen, 2004). The likelihood of these outcomes is highly dependent on intrinsic factors, such as the extent of reproductive isolation, as well as extrinsic factors, because hybrid fitness may be dependent on the environment (Coyne, 2004). The study of multiple contact regions of the same species pair allows to test the consistency of hybridization outcomes (Harrison \& Larson, 2016). Thus, when the range of two closely related species is large and overlapping, and if this overlap results in hybridization, then hybridization at several spatial scales can provide insights into parallel patterns of hybridization in different demographic and ecological contexts (Abbott et al., 2013). Several empirical studies, mainly from plants (Buerkle \& Rieseberg, 2001; Haselhorst \& Buerkle, 2013; Sweigart, Mason, \& Willis, 2007) and fishes (Aboim, Mavárez, Bernatchez, \& Coelho, 2010; Mandeville et al., 2017; Nolte, Gompert, \& Buerkle, 2009), but also from mammals (Good, Handel, \& Nachman, 2008), amphibians (Vines et al., 2003) and insects (Gompert et al., 2014), have shown that the outcomes of hybridization varies among hybrid regions of the same species pairs while only few studies have shown consistency in the pattern, e.g., in plants (Buerkle \& Rieseberg, 2001) and insects (Larson, White, Ross, \& Harrison, 2014). Detecting parallelism in the prevailing genomic signatures allows gaining insights into the process of hybridization itself, for example, if species have genomic regions that introgress more readily than others.

Odonata are a group that is heavily affected by increasing temperatures and many species are changing their distributions (Hassall \& Thompson, 2008; Hassall, Thompson, \& French, 2007; Hickling, Hill, \& Thomas, 2005; Lancaster et al., 2016; Ott, 2010). Within odonates, the damselfly genus Ischnura is extremely species rich (around 70 species) (Dijkstra \& Kalkman, 2012; Sánchez-Guillén et al., 2020) and includes many closely related and recently diverged species that co-occur in partial sympatry over parts of their range (Sánchez-Guillén, Muñoz, Rodríguez-Tapia, Arroyo, \& Córdoba-Aguilar, 2013; Wellenreuther \& SánchezGuillén, 2015). This genus has also other interesting properties such as high local abundances and wideranging distribution patterns, and it is highly enabled for field identification and sampling, making this a suitable group to explore adaptive introgression caused by environmental change. Indeed, there are several examples of extensive hybridization between species within the Ischnura genus, for example, between I. denticollis and the endangered I. gemina in the San Francisco Bay (Leong \& Hafernik, 1992; SánchezGuillén et al., 2014), and in Europe between I. graellsiiand I. saharensis, and between I. genei and I. elegans (Sánchez-Guillén, Córdoba-Aguilar, Cordero-Rivera, \& Wellenreuther, 2014).

However, the best documented and explored case of hybridization inIschnura is between I. elegans and I. graellsii in Spain (Monetti, Sánchez-Guillén, \& Cordero Rivera, 2002; Sánchez-Guillén, van Gossum, \& Cordero-Rivera, 2005; Sánchez-Guillén, Wellenreuther, \& Cordero-Rivera, 2012; Wellenreuther et al., 2018).Ischnura elegans and I. graellsii are among the most frequently studied damselfly species within the order Odonata, and as such have become eco-evolutionary model species that have been studied extensively for hybridization and reproductive isolation (Monettiet al. , 2002; Sánchez-Guillén et al. , 2005, 2011, 2012, 2014b; Wellenreuther \& Sánchez-Guillén, 2016; Wellenreuther et al. , 2018). Ischnura elegans and I. graellsii are closely related and share many morphological, genetic and phenotypic traits (Sánchez-Guillén et al., 2011), including preference traits for habitats, and they occupy similar ecological niche space in Spain (Wellenreuther et al., 2018). Ischnura elegans has dramatically expanded its distribution in Spain during last 40 years (Sánchez-Guillén et al., 2011), where its distributional range nowadays overlaps almost completely with I. graellsii (Fig. 1A-B), which is endemic to Spain and Maghreb in north-western Africa. The Mediterranean coast represents the oldest hybrid region with the firsts records of $I$. elegans in the late $19^{\text {th }}$ century (Ocharan, 1987), with increasing records over the country from the early 1980s and onwards (Ocharan, 1987), and a fast expansion from 2000 to the present (Fig. 1B). A previous molecular study with microsatellites 
estimated that in the Spanish hybrid populations $55-60 \%$ of the I. elegans individuals were introgressed or backcrossed, and that from 10-30\% were $\mathrm{F}_{1}$ or $\mathrm{F}_{2}$ hybrids (Sánchez-Guillén et al., 2011). In the Spanish hybrid region, I. elegans has replaced I. graellsii from the coast and modified its original environmental niche to become more similar to the I. graellsii niche (Wellenreuther et al., 2018).

In the present study, we focus on two hybrid regions in Spain, one in north-west Spain (Galicia) and one in north-central Spain (La Rioja, Navarra and Avila). We used Restriction site-Associated DNA (RAD) sequencing and a recent $I$. elegans reference genome assembly (Chauhan et al., 2021) to identify genomewide SNPs in individuals from the two hybrid regions as well as from eight allopatric populations from both species in Spain and adjacent countries. First, we used species-specific SNPs to analyze the fine-scale individual ancestry and proportion of individuals in different hybrid classes (ranging from pure individuals to $\mathrm{F}_{1}$ and $\mathrm{F}_{2}$ hybrids). With this analysis we were particularly interested in confirming the occurrence of hybrids and backcrosses, and in evaluating the local and regional scales of hybridization dynamics. We used data on the strength of reproductive barriers and colonization history in an aim to explain the present-day hybridization patterns. Second, we used the full set of SNPs to compare the degree genetic variation and genetic differentiation in the Spanish hybrid regions and adjacent allopatric regions. With these analyses we were interested in evaluating whether hybridization and introgression have increased the level of genetic variation of individuals in the different hybrid classes. We discuss our results in light of parallelism in hybridization and introgression within and between regions, or the lack thereof, and in relation to previous data on biased mating success among I. elegans and I. graellsii. This work is a step towards understanding the potential role of hybridization and introgression in facilitating range expansions.

\section{MATERIAL AND METHODS}

\subsection{Populations sampling}

\subsubsection{Allopatric populations}

Ischnura elegans extends from Greece to Sweden while I. graellsii is an Iberian-Maghreb endemic species with a more restricted range in western North Africa and the Iberian Peninsula (Askew, 1989). We sampled individuals from five populations from the allopatric distribution of $I$. elegans and in three populations from the allopatric distribution of I. graellsii (Fig. 1A; Table 1). These allopatric populations were selected to cover a large part of their latitudinal distribution, with the aim of including a large and representative amount of the total genetic variation.

\subsubsection{Sympatric populations}

During fieldwork in the years 2014-2018 in north-central and north-west Spain, we conducted a revision of the distribution data of both species along the Iberian Peninsula from 2011 (reviewed in Boudot et al., 2009). From two hybrid regions, north-central Spain (Arreo, Cañas, Mateo, Perdiguero, Valbornedo, Valpierre, and Villar) and north-west Spain (Doniños, Laxe, Louro and Xuño) we included populations in which: 1) $I$. elegans was the dominant species; 2) I. graellsiiwas the dominant species, and 3) both species were present at different proportions. Additionally, available information of presence/absence from previous years (19872003) was also included. Populations were visited between June and July during sunny days, and sampling was done with entomological nets. Immature and mature males were included when estimating the number of individuals in each species (species proportion). Additionally, we included one population from north-east Spain (Menorca, in the Balearic Islands) to test the replacement of I. graellsii by I. elegans in the Balearic Islands (results are given in supplementary Figure S4).

For the genomic work, a minimum of 20 adult males were collected during the flight season between 2008-2015 using hand nets and stored in 100\% ethanol until DNA extraction. Because phenotypic hybrid assignment is only possible through detailed morphological analyses of male caudal appendages and prothoracic tubercle (see Monetti et al., 2002), all individuals in this study (of which a majority were females) werea priori morphologically assigned to either I. elegans or I. graellsii based on their thorax colour and prothoracic 
tubercle morphology. For populations with both species (I. elegans and I. graellsii ), we included samples of both species and aimed to keep the species proportion observed in the field at each site (Table 1). Previous data and our results allow us to discuss the present results in a time- and space-frame context.

\subsection{Reproductive isolation}

Mating incompatibility between I. graellsii males and I. elegans and hybrid females is known in populations from the north-west hybrid region (Sánchez-Guillén, Wellenreuther, \& Cordero-Rivera, 2011), but not its potential temporal and spatial variation. Thus, the strength of the reproductive barriers involved in preventing copulation in north-central was used to test temporal and/or spatial variation. Similar data from northwest populations are available from an unpublished study (Arce-Valdés, Ballén-Guapacha, Chávez-Rios \& Sánchez-Guillén, under review).

For reproductive isolation analysis, last instar larvae of approximately $200 \mathrm{I}$. elegans and $200 \mathrm{I}$. graellsii individuals, both from north-central Spain (Mateo, Valbornedo and Villar), were sampled in June-July of 2016-2017. Larvae were transported to the laboratory and maintained until adulthood (for details about larval rearing methodology see Sánchez-Guillén et al., 2005; Van Gossum, Sánchez-Guillén \& Cordero-Rivera, 2003). Mechanical isolation to reach the copulation was estimated by measuring incompatibility between the male cerci and female prothorax (males attempt to grasp females) and the incompatibility between male-female genitalia (both genitalia come into contact), in heterospecific crosses of I. elegans with I. graellsiifemales, and I. graellsii males with I. elegansfemales. Additionally, hybrids in the laboratory (from crosses betweenI. elegans and I. graellsii ) were used to produce backcrosses to measure mechanical isolation in both directions (hybrid males with $I$. elegans females and I. elegans females with hybrid females; and hybrid males with $I$. graellsii females and I. graellsii males with hybrid females).

\subsection{Genome-wide SNP markers}

\subsubsection{DNA extraction and RAD library preparation}

Genomic DNA from head and thorax tissues of 187 individuals from the 20 populations (6-10 individuals per site; Table 1) was extracted with Qiagen DNeasy Blood \& Tissue Kit. Extracted DNA was quantified using Nanodrop and visually controlled for DNA degradation using a 1\% agarose gel. Five single-digest RAD DNA libraries were processed according to the protocol implemented in Etter et al. (2011) and modified in Dudaniec et al. (2018). All samples, plus five sample replicates, were distributed across the five separately prepared RAD libraries with 40 unique barcodes used per library (sourced from Metabion). Each library was paired-end sequenced $(2 * 100 \mathrm{bp})$ on a separate lane of an Illumina HiSeq 2500 at SNP\&SEQ Technology Platform at Uppsala University, yielding 180 million read pairs per lane (i.e. per library).

\subsubsection{Quality checking and SNP calling}

Libraries were processed using pipelines within STACKS v2.2 (Catchen, Hohenlohe, Bassham, Amores, \& Cresko, 2013; Catchen, Amores, Hohenlohe, Cresko, \& Postlethwait, 2011). Raw reads were demultiplexed with process_radtags and PCR clones were identified and discarded with clone_filter using default parameters. Sequence reads were aligned to the I. elegans draft genome assembly (Chauhan et al., 2021) using BOWTIE2 v.2.3 (mismatch allowance per seed alignment of 1, maximum mismatch penalty of 6 and minimum of 2, maximum fragment length of $1000 \mathrm{bp}$ and minimum of $100 \mathrm{bp}$, Langmead \& Salzberg, 2012). We used the ref_map pipeline to detect SNPs using default parameters. Only SNPs with a minor allele frequency of $>0.05$ and a maximum observed heterozygosity of 0.7 were retained. Moreover, the locus had to occur in $80 \%$ of the individuals in a population and in 18 of the 20 populations to be included in the final SNP set. SNP markers were filtered to include only a single random SNP on each RAD tag to create a data set without closely linked loci (using the write_single_snp option in STACKS). Finally, by using the I. elegans reference genome (Chauhan et al., 2021) SNPs were filtered to include only those located on autosomal scaffolds.

Exploratory analyses of population structure revealed possible hybridization in two of the I. graellsii samples 
from Seyhouse (Algeria); probably with a third Ischnura species (see Supplementary Figure S1). These two samples were removed from further analyses leaving the final total sample size of 185 (Table 1).

\subsubsection{Identification of species-specific loci}

Diagnostic species-specific loci are powerful markers for assigning later generation hybrids and detecting introgressed alleles in population genetic studies (Hohenlohe, Amish, Catchen, Allendorf, \& Luikart, 2011). To provide a list of species-specific markers, alternatively fixed SNPs between the parental species from the allopatric distribution ( $\mathrm{n}=43$ I. elegans and $\mathrm{n}=25$ I. graellsii $)$ were identified using VCFtools v0.1.16 (Danecek et al., 2011). SNPs for each of the two allopatric regions that had only one allele (-max-maf 0) were selected, and then, shared loci between the two allopatric regions were found using the intersect( ) function of R (R Core Team, 2016). Following that, we applied to those loci the Hardy-Weinberg test implemented in VCFtools ( $-h a r d y)$, and removed loci fixed for the same allele in the two species $\left(\mathrm{H}_{\mathrm{E}}=0\right)$. The remaining 381 SNPs (out of the 5,702 SNPs) were considered as the species-specific markers set.

\subsection{Hybridization analyses}

\subsubsection{Assignment to hybrid classes: Hybrid Index (HI) and Heterozygosity (Het)}

We used the R package INTROGRESS v1.2.3 (Gompert \& Alex Buerkle, 2010) to calculate individual introgression coefficients; hybrid index (HI-values) and individual heterozygosity (HET-values), and used both of them to classify individuals into different hybrid classes (c.f. Jordan et al., 2018). INTROGRESS was used with the subset of 381 species-specific SNPs, as the assignment to hybrid classes can be inexact when using nondiagnostic markers (Buerkle, 2005). INTROGRESS when using species-specific allele SNPs, calculates the hybrid index as the proportion of alleles inherited from one species, and the heterozygosity, as the proportion of alleles that are heterozygous, ranging from 0 (pure species) to 1 ( $\mathrm{F}_{1}$ hybrids) because of pure species are 100\% homozygous, while $\mathrm{F}_{1}$ hybrids are $100 \%$ heterozygous (Gompert \& Buerkle, 2010). Thus, the HI-value gives the proportion of alleles inherited from one species, in this caseI. elegans (e.g. $1.00=100 \%$ I. elegans, and $0.00=100 \%$ I. graellsii, alleles), whereas HET-values, which range from 0.00 to $1.00(0.00=$ all sites are homozygous, $1.00=$ all sites are heterozygous $)$, indicate the timing of the hybridization event. First generation hybrids ( $\mathrm{F}_{1}$ individuals) are expected to be heterozygous at all species-specific SNPs, while later-generation hybrids and backcrosses will have a lower heterozygosity levels, and the HI-values of $\mathrm{F}_{1}$ and $\mathrm{F}_{2}$ individuals will be close to 0.5 , while backcrosses will have a HI-value below (or up to) 0.5 (Fitzpatrick, 2012). However, because of the lack of pure I. elegans and pure I. graellsii in the three hybrid regions [only 3 out of the 102 individuals were pure I. elegans (2) or pure I. graellsii (1)], criteria for $F_{1}$ and $F_{2}$ hybrid classes were relaxed. Thus, we classified individuals into eight parental and hybrid classes (cf., Milne \& Abbott, 2008; Walsh et al., 2015): (i) pure I. elegans (HI=1.000; HET[?]0.000), (ii) pure I. graellsii ( $\mathrm{HI}=0.000$; HET[?]0.000), (iii) introgressed-elegans ( $\mathrm{HI}=0.900-0.999$; HET[?]0.118), (iv) introgressed-graellsii ( $\mathrm{HI}=0.001-0.100$; HET[?]0.118), (v) backcross-elegans ( $\mathrm{HI}=0.601-0.899$; HET $=0.118$ 0.449 ), (vi) backcross-graellsii ( $\mathrm{HI}=0.101-0.399$; $\mathrm{HET}=0.118-0.449)$, (vii) relaxed $\mathrm{F}_{1}$ hybrids $(\mathrm{HI}=0.400-$ 0.600; HET[?]0.600), and (viii) relaxed $\mathrm{F}_{2}$ hybrids ( $\left.\mathrm{HI}=0.400-0.600 ; \mathrm{HET}=0.450-0.599\right)$.

To investigate whether the hybrid regions have similar proportions of hybrid classes, the observed hybridclass distributions of individuals from north-central and north-west (north-east was not included in the statistical analyses due to small sample sizes) were used to estimate the predicted distribution of individuals in admixture-classes using a contingency table (assuming random distribution) and then compared to the observed admixture-class distribution in both hybrid regions. Z-tests with Yates's corrections for small sample sizes were used to test for differences in the proportions of each hybrid class category between northwest and north-central hybrid regions.

The twelve analyzed populations from the Spanish hybrid zone were assigned to three qualitative measures that reflects their genotypic compositions. This classification depends on the frequency distribution of the different hybrid classes: 1) unimodal hybridization pattern, when the distribution spans a range of admixture and backcrosses towards both parental species; 2) bimodal hybridization pattern, when the distribution is deviated to the two parental or parental-like genotypes, and few hybrids ( $F_{1}$ and $F_{2}$ hybrids) are present 
(Jiggins \& Mallet, 2000); and 3) introgressed hybridization pattern when the distribution was deviated to one parental-like genotype.

\subsection{Population genetic analysis of the Spanish hybrid region}

\subsubsection{Structure and principal component analyses}

ADMIXTURE v1.3.0 (Alexander \& Lange, 2011) was run using the set of 5,702 SNPs and all samples to evaluate the genetic structure among populations. ADMIXTURE was run using the "unsupervised model" (without using sampling locality as a prior). With this model setting, ADMIXTURE evaluates $Q$ - values to ancestral genetic clusters $(\mathrm{K})$ in different runs, ranging from one $(\mathrm{K}=1)$ to the number of sampled populations +1 (in our case $\mathrm{K}=21$ ), and gives an optimal $\mathrm{K}$ as the one achieving the lowest cross-validation (cv) error. Furthermore, ADMIXTURE was also run using the subset of 381 SNPs ("unsupervised model") and all populations to compare the genetic structure among populations suggested by the set of species-specific SNPs to the structure suggested by the complete set of SNPs. ADMIXTURE was run using K values (1 to 15), the reason for this was the reduction in the number of localities due to the use of all allopatric samples as a single fixed population for both species.

To visualize patterns of genetic differentiation among individuals and populations, we used principal component analyses (PCA) in the R package SNPRelate v1.6.4, function snpgdsPCA() (Zheng et al., 2012), using the set of 5,702 SNPs and all samples. This was used to determine whether individuals from the allopatric regions and the two hybrid regions correspond to different genetic clusters.

\subsubsection{Genetic diversity and Hardy Weinberg equilibrium}

To test whether potential hybridization and introgression resulted in increased genetic diversity in the Spanish hybrid regions, we compared different genetic diversity estimates for I. elegans and I. graellsii from the allopatric and the sympatric distribution in each locality, for all individuals before excluding the hybrids ( $\mathrm{F}_{1}$ and $\mathrm{F}_{2}$ hybrids) and after excluding hybrids. We calculated number of alleles $(\mathrm{A})$, allelic richness $(\mathrm{Ar})$, observed heterozygosity $\left(\mathrm{H}_{\mathrm{O}}\right)$, expected heterozygosity $\left(\mathrm{H}_{\mathrm{E}}\right)$, and nucleotide diversity $(\pi)$ using the 5,702 SNPs set. Genetic diversity was measured at both population and regional levels. Na, and Ar were estimated using the HIERFSTAT package v0.04-22 (Goudet, 2005) as implemented in R. Allelic richness was rarefacted for a minimum of eight alleles (or four diploid samples), which was the lowest sample size used for HardyWeinberg equilibrium testing. Meanwhile $\mathrm{Ho}$ and $\mathrm{H}_{\mathrm{E}}$ were calculated using PLINK v1.90b6.12 (Purcell et al., 2007), and $\pi$ and the percentage of SNPs with missing data (NA) with VCFtools. Kruskal-Wallis tests and posthoc paired Wilcoxon tests were used to compare the levels of each diversity estimate between regions (north-west and north-central hybrid regions, and allopatry).

Population and regional tests for Hardy-Weinberg disequilibrium per locus were estimated using the 5,702 SNPs using PLINKs mid-p modifier (Graffelman \& Moreno, 2013). Then, the ratios of SNPs at HW disequilibrium $(p<0.05)$ to the total number of genotyped SNPs, as well as average $p$-values per population were calculated.

\subsubsection{Genetic differentiation between species}

Overall and pairwise differentiation was assessed using the complete set of 5,702 SNPs by calculating $\mathrm{F}_{\mathrm{ST}}$ (Weir and Cockerham 1984) using 10,000 bootstraps with the R package StAMPP v1.6.1 (Pembleton, Cogan, \& Forster, 2013). To test whether hybridization and introgression resulted in reduced differentiation between species in sympatry, we first compared overall genetic differentiation betweenI. elegans and I. graellsii from allopatry with the overall genetic differentiation between I. elegans and I. graellsii from the Spanish hybrid region (including all individuals minus the $\mathrm{F}_{1}$ and $\mathrm{F}_{2}$ hybrids). Second, pairwise genetic differentiation among localities was calculated for I. elegans and I. graellsii, for all individuals before excluding the hybrids, and for all individuals minus the $\mathrm{F}_{1}$ and $\mathrm{F}_{2}$ hybrids.

\section{RESULTS}

\subsection{Local dynamics}


Ischnura elegans has increased its presence in central Spain over the last ten years. Currently, it is present in 32 provinces (in 8 provinces since at least 1900, in 21 since 1980, and in 32 since 2000; see Fig 1B), and although it is not yet a resident in 15 southern provinces, observations of $I$. elegans in the field are increasing also in these provinces.

The twelve populations from the Spanish hybrid region were sampled at least four times over a period of 4-10 years (north-central hybrid region) and a period of 4-5 years (north-west hybrid region). Data from this study, and available data from previous studies were compiled as documented in (Supplementary Table S2). In the north-central hybrid region, studied localities were frequently subjected to desiccation (and therefore recolonization) because of water is used for irrigation of neighbouring wine crops, or by management of invasive species (mainly American crab). Cañas, Perdiguero and Villar all periodically dry up, and a recolonization from nearby populations of both species is regularly happening. In fact, Cañas and Villar were emptied and recolonized a couple of years before we sampled them. During the studied 4 years, at least two recolonization events were recorded. In this region, species proportions were unstable, and the seven studied localities were sympatric (at different species proportions) at the end of the study in 2018 (see Table 2). However, although studied localities in the north-central hybrid region were also exposed to recolonization events, but in this case, by natural desiccation (evaporation) or by brought brackish water event (lagoon retro dune), species proportions were stable in the studied period (Table 2).

\subsection{Reproductive isolation}

In both hybrid regions, i.e., north-central and north-western Spain, we detected strong and asymmetric mechanical reproductive isolation. In north-central Spain, mechanical and tactile barriers between I. elegans males and I. graellsii females impeded $65 \%$ of the matings, while between I. graellsii males and I. elegans females $76 \%$ of matings were impeded. When those barriers were estimated in I. elegansbackcrosses, i.e., between I. elegans males and hybrid females, barriers impeded $33 \%$ of the matings, while between hybrid males and I. elegans females, barriers impeded $75 \%$ of matings. More isolation was detected in I. graellsii backcrosses, betweenI. graellsii males with hybrid females $100 \%$ of the copulations were prevented, but we find no isolation between hybrid males andI. graellsii females (0\%) (Figure 2A). The strength of mechanical and tactile barriers in heterospecific crosses and I. elegans and I. graellsii backcrosses in north-western Spain are given in Figure 2B [data from (Arce-Valdés, Ballén-Guapacha, Chávez-Rios, \& Sánchez-Guillén, under review; Sánchez-Guillén et al., 2012)].

\subsection{Complete set of SNPs and species-specific SNPs}

A total of 5,702 SNPs were detected after stringent filtering and of those, 2,127 (37.3\%) were polymorphic in I. elegans but invariable in I. graellsii , and 1,711 (30.0\%) were polymorphic in I. graellsii but invariable in I. elegans . Of the remaining, 1,421 (24.9\%) were polymorphic in both species, $62(1.1 \%)$ fixed for the same allele in allopatric I. elegans and I. graellsii, and 381 (6.7\%) species-specific, i.e., alternatively fixed between I. elegans and I. graellsii individuals from the allopatric populations (Supplementary Table S3). Note that our set of species-specific alleles, which was determined by comparing 43 allopatric I. elegans and 25 allopatric I. graellsiiindividuals, might not represent entirely fixed alleles, but represent alleles with highly skewed frequencies between our species groups (see Fitzpatrick, 2012; Jordan et al., 2017).

\subsection{Individual introgression coefficients, heterozygosity, and assignment to hybrid classes}

Introgression analyses using the set of species-specific SNPs were used to classify individuals in the Spanish hybrid regions into eight hybrid classes (pure I. elegans, pure I. graellsii, introgressedI. elegans, introgressed I. graellsii, backcross toI. elegans, backcross to I. graellsii, $\mathrm{F}_{1}$ and $\mathrm{F}_{2}$ hybrids) (Table 3 ; Fig. 2C-D). Samples that were a priori morphologically identified as I. elegans were classified in three classes: pure I. elegans , introgressed I. elegans and I. elegans backcrosses. Introgressed I. elegans represented the larger proportion of individuals (59 out of 65 ) in both hybrid regions, while only four $I$. elegansbackcrosses were found (all in the north-west hybrid region) and only two pure I. elegans (one in north-central and one in north-west; Table 3; Fig. 2C-D). Samples a priori morphologically identified as I. graellsii were classified into five classes: pure I. graellsii, introgressed I. graellsii, back to I. graellsii, $\mathrm{F}_{1}$ and $\mathrm{F}_{2}$ hybrids. Introgressed I. graellsii was 
the category that included the larger proportion of individuals (37 out of 52) in both hybrid regions [note morphologically I. graellsii were not present in the Menorca from the north-east hybrid region], followed by nine $\mathrm{F}_{1}$ and $\mathrm{F}_{2}$ hybrids, five I. graellsii backcrosses in both hybrid regions and one pure I. graellsii in north-central Spain (Table 3; Fig. 2C-D).

To investigate whether the north-west and north-central hybrid regions had a similar hybridization pattern, hybrid class proportions were compared with Z tests using Yates's corrections for small sample sizes. We found that both regions showed similar hybrid class proportions for all hybrid classes except for the class I. elegans introgressed (that showed a non-significant trend; $?^{2}=3.438, \mathrm{df}=1, p=0.063$ ) and for $I$. elegans backcrossed $\left(?^{2}=6.181, \mathrm{df}=1, p=0.013\right)$, where the north-west hybrid region had higher proportions. Additionally, when hybrid class proportions were analyzed by population, we found extensive introgression in most populations and ongoing hybridization ( $F_{1}$ and $F_{2}$ hybrids) in four localities (Canas, Perdiguero, Villar and Louro) (Fig. 3A). Three hybridization patterns were detected in the twelve populations: 1) a bimodal pattern in five populations (Arreo, Canas, Perdiguero, Valbornedo, and Villar); 2) an introgressed pattern in five populations (Mateo, Valpierre, Doninos, Laxe and Xuno); and a unimodal pattern in one population (Louro) (Fig. 3B).

\subsection{Population genetic analysis of the Spanish hybrid region}

\subsubsection{Structure and principal component analyses}

Genetic structure analyses were done using the whole set of 5,702 SNP with ADMIXTURE, without and with supervision (i.e., using the allopatric samples as ancestry references) (Supplementary Figure S4). Analyses without supervision indicated that the most likely number of ancestral populations (i.e., the $\mathrm{K}$ with the lowest cv error) was $\mathrm{K}=2$ (Supplementary Figure S5), but it should be noted that the cv errors for $\mathrm{K}=2$ and $\mathrm{K}=3$ were similar. For $\mathrm{K}=2$, the two genetic clusters corresponded very well to $I$. graellsii and $I$. elegans , respectively, and for $\mathrm{K}=3$ a third cluster was found among I. eleganspopulations from the north-west hybrid region. For both $\mathrm{K}=2$ and $\mathrm{K}=3$, many samples with admixed ancestry were present (Supplementary Figure $\mathrm{S} 4)$.

PCA allowed us to cluster I. elegans, I. graellsii and hybrids from allopatry and from the three hybrid regions. The first axis of the PCA explained $39 \%$ of the total variation and clearly separated $I$. elegans and $I$. graellsii individuals from allopatric localities, while the second axis explained $2 \%$ of the total variation and separated some of the individuals from north-central and north-west hybrid regions (Supplementary Figure S6). Consistent with the ADMIXTURE results, many individuals from the three hybrid regions appeared in the same PCA quadrant as those occupied by the pure species from the allopatric distribution, while hybrids occupied intermediate positions of the first axis.

\subsubsection{Genetic diversity and Hardy Weinberg equilibrium}

Hybridization and introgression resulted in an increase of genetic diversity ( $\pi$, A, Ar, Ho and $\mathrm{H}_{\mathrm{E}}$ ) in the hybrid regions, which was estimated with the whole set of 5,702 SNPs (Figure 4 and Supplementary Tables S7- S9). When the genetic diversity parameters were compared between I. elegans from allopatry and I. elegansfrom sympatry in each of the hybrid regions excluding $\mathrm{F}_{1}$ and $\mathrm{F}_{2}$ hybrid individuals, significant differences in all five estimates $\left(\pi, \mathrm{Na}, \mathrm{Ar}, \mathrm{Ho}\right.$ and $\mathrm{H}_{\mathrm{E}}$ ) were detected for the north-west hybrid region (all estimates were higher in the north-west hybrid region; Figure 4 and Supplementary Tables S7- S9). We also found significantly higher $\mathrm{Ar}$, Ho and $\mathrm{H}_{\mathrm{E}}$ in the north-west hybrid region compared to the north-central hybrid region (Figure 4 and Supplementary Tables S7-S9). Similarly, when comparing I. elegans from allopatry and I. elegans from sympatry in each of the hybrid regions not excluding $F_{1}$ and $F_{2}$ hybrids, all estimates of genetic diversity $\left(\pi, \mathrm{A}, \mathrm{Ar}, \mathrm{Ho}\right.$ and $\left.\mathrm{H}_{\mathrm{E}}\right)$ were significantly higher for the north-west hybrid region than for I. elegans from sympatry and than for I. elegans from the north-central hybrid region (Figure 4 and Supplementary Tables S7- S9). No significant differences between regions were detected in the ratio of SNPs at HW disequilibrium per population ( $<<0.05$; see Supplementary Tables S8-S9).

\subsubsection{Genetic differentiation between and within species in allopatry and sympatry}


Consistent with the finding that hybridization, admixture and introgression results in reduced interspecific differentiation in sympatry, we found that the overall genetic differentiation between I. elegans and I. graellsii was lower in the sympatric (excluding $\mathrm{F}_{1}$ and $\mathrm{F}_{2}$ hybrids) $\left(\mathrm{F}_{\mathrm{ST}}=0.691\right)$ than in the allopatric distribution $\left(\mathrm{F}_{\mathrm{ST}}=0.725\right)$.

Pairwise intraspecific population differentiation in $I$. elegans from allopatry ranged from $\mathrm{F}_{\mathrm{ST}}=0.002-0.245$ ( 8 out of the 10 pairwise $\mathrm{F}_{\mathrm{ST}}$ values were significant at the $p<0.05 / 10$ ), from the north-west hybrid region (excluding $\mathrm{F}_{1}$ and $\mathrm{F}_{2}$ hybrids) ranged from $\mathrm{F}_{\mathrm{ST}}=0.012-0.100$ ( 3 out of the 3 pairwise $\mathrm{F}_{\mathrm{ST}}$ values were significant at the $p<0.05 / 3$ ), from the north-central hybrid region (excluding $\mathrm{F}_{1}$ and $\mathrm{F}_{2}$ hybrids) ranged from $\mathrm{F}_{\mathrm{ST}}=0.004-0.013$ ( 1 out of the 10 pairwise $\mathrm{F}_{\mathrm{ST}}$ values was significant at the $p<0.05 / 10$ ) (Supplementary Table $\mathrm{S} 10)$. Pairwise intraspecific population differentiation in $I$. graellsii from allopatry ranged from $\mathrm{F}_{\mathrm{ST}}=0.008$ 0.068 ( 2 out of the 3 pairwise $\mathrm{F}_{\mathrm{ST}}$ values were significant at the $p<0.05 / 3$ ), from the north-west hybrid region $\mathrm{F}_{\mathrm{ST}}=0.042$ ( 1 out of the 1 pairwise $\mathrm{F}_{\mathrm{ST}}$ values was significant at the $p<0.05$ ), and from the northcentral hybrid region ranged from $\mathrm{F}_{\mathrm{ST}}=0-0.014$ ( 0 out of the 15 pairwise $\mathrm{F}_{\mathrm{ST}}$ values was significant at the $p$ $<0.05 / 15$ ) (Supplementary Table S11).

Some populations were highly genetically distinct from many populations. Specifically, the $I$. elegans Doniños population from the north-west hybrid region showed comparatively large and statistically significant genetic differences with several other populations (Supplementary Tables S10-S11). Similarly, the I. elegans Leuven population and the I. graellsii Seyhouse population from the allopatric distributions showed comparatively large and statistically significant genetic differences with several other populations (Supplementary Tables S10-S11).

\section{DISCUSSION}

Proximity to the introduction site and local dynamics

Our admixture analysis with the set of species-specific loci showed bidirectional introgressive hybridization between I. elegans andI. graellsii . Individuals from both hybrid regions, north-west and north-central Spain, mainly belonged to the introgressed I. elegans and introgressed I. graellsii classes, and less frequently to the backcross to I. elegans, backcross to I. graellsii, $\mathrm{F}_{1}$ and $\mathrm{F}_{2}$ hybrid classes. Almost no pure I. elegans or pure I. graellsii were found in the hybrid regions.

When comparing the distribution of parental and hybrid classes between north-west and north-central hybrid regions, all classes were at similar frequency proportions except for the introgressed I. elegans class, which was significantly higher in the north-west hybrid region. The proximity to the introduction or source locality could affect hybridization outcomes (Fitzpatrick et al., 2010; Lepais et al., 2009), as the rate and directionality of introgression can be influenced by the species' relative abundance and therefore by gene flow from the native to the non-native species. A non-native colonising species is usually rare and matings with the native species are likely, as was detected in other studied organisms (Fitzpatrick et al., 2010; Lepais et al., 2009; Quilodrán, Nussberger, Montoya-Burgos, \& Currat, 2019). Introgressed genes can reach high frequency in the non-native species by a rapid demographic growth, resulting in asymmetric introgression of neutral genes (Currat, Ruedi, Petit, \& Excoffier, 2008). The north-central hybrid region is closer to the allopatric distribution of $I$. elegans and disconnected to the I. elegans populations from the north-west hybrid region. In fact, the number of populations dominated by $I$. elegans, and the abundance of $I$. elegans in populations with both species in the north-western hybrid region is lower than in the north-central hybrid region which is closer to the allopatric distribution of I. elegans (Boudot et al., 2009; Sanchez-Guillen, Van Gossum, \& Cordero Rivera, 2005; Sánchez-Guillén et al., 2011)

In both hybrid regions local populations showed pronounced variation in species composition and in the degree of hybridization and introgression, which suggests that the local dynamics is even more distinct than the regional dynamics in this system (Fig. 2A-B). In four out of the six study populations where both species co-occur at different numbers (Cañas, Louro, Perdiguero and Villar), nine individuals morphologically classified I. graellsii were genetically assigned to $\mathrm{F}_{1}$ or $\mathrm{F}_{2}$ hybrid classes. This is consistent with observations in the laboratory that $\mathrm{F}_{1}$ hybrids are morphologically similar to I. graellsii (Sanchez-Guillen et al., 2005), 
and independent of the reciprocal cross direction (I. elegans male mated with I. graellsii or hybrid female, or I. graellsii male mated withI. elegans or hybrid female) that has produced the $\mathrm{F}_{1}$ or the $\mathrm{F}_{2}$ hybrid (RAS-G personal observation). Local dynamics was dominated by periodic dry-ups followed by recolonizations by one or both species. For instance, Cañas and Villar (north-central populations) were emptied and recolonized a couple of years before we sampled them. Similarly, the north-western population Louro became extinct due to salobrisation by seawater in 2009, and was recolonized by both species, forming a hybrid population with high levels of admixture. In Arreo and Valbornedo we did not detect $F_{1}$ or $F_{2}$ hybrids, even though both species are present. Even the six studied populations with only one of the genotypical-parental species [Doniños, Laxe and Menorca (onlyI. elegans ), and Mateo, Valpierre and Xuño (only I. graellsii )] showed different levels of introgression or back crosses, indicating that although only one species was detected in the sampling years both species were possibly present in the population in the years before. This can be the case of Xuño that had both species during 2003-2006 and was naturally dried in 2007 and after that recolonized by I. graellsii, which explains the observed levels of admixture.

Strength of the prezygotic reproductive barriers

Differential outcomes of hybridization may partly be explained by the strength of the prezygotic reproductive barriers (Lepais et al., 2009; Mandeville et al., 2017; Vines et al., 2003) which varies across species (Good et al., 2008; Sánchez-Guillén et al., 2014) and in hybridizing species, with the time since sympatry (Kronforst, Young, \& Gilbert, 2007; Lemmon \& Juenger, 2017; Liao et al., 2019). The frequency distribution of hybrid classes in a hybrid zone may reflect the strength and direction of reproductive barriers. A bimodal distribution of the genotypical-like classes (parental or introgressed individuals) are thought to be the consequence of strong but incomplete reproductive isolation (e.g., Harrison \& Bogdanowicz, 1997), while lower levels of prezygotic isolation resulting in a unimodal distribution on the genotypic classes (the distribution spans a range of admixture and backcrosses toward both parents) (e.g., Szymura \& Barton, 1991) (Gompert, Mandeville, \& Buerkle, 2017; Jiggins \& Mallet, 2000).

The high prevalence of admixed individuals in north-central Spain can be explained by its level of reproductive isolation as was, for instance, detected in Catostomus fish species (Mandeville et al., 2017) and intertidal snails (Littorinids) (Stankowski et al., 2020). In north-central Spain, $70 \%$ of the heterospecific matings between phenotypically I. elegans and I. graellsii were prevented, while the backcrosses to I. elegans and the backcrosses toI. graellsii were less and similarly prevented (54\% and $50 \%$, respectively). In fact, from the north-central hybrid region, five populations (Arreo, Cañas, Perdiguero, Valbornedo and Villar) show a bimodal distribution (introgressed individuals with $I$. elegansand $I$. graellsii ) and Mateo and Valpierre presented an introgressed distribution (introgressed individuals with $I$. graellsii). However in the north-west hybrid region, heterospecific matings and backcrosses with I. elegans were similar and strongly prevented ( $80 \%$ and $79 \%$ respectively), while only $46 \%$ of the backcrosses with I. graellsii were prevented. Arce-Valdéset al. (under review) found evidence of an incipient strengthening of the prezygotic isolation in this hybrid region. From the north-west hybrid region, three populations (Doniños, Laxe, Xuño) presented an introgressed distribution towards I. elegans(Doniños, Laxe) and towards I. graellsii (Xuño), and one population (Louro) presented a unimodal pattern. Differences in the admixture-class distributions between the Spanish hybrid regions (I. elegansclass was significantly higher in the north-west hybrid region) can be explained by the reinforcement of the strength of the reproductive isolation between I. elegans and I. graellsii in the north-west hybrid region.

Range expansion and time elapsed since the colonization

A common signature of range expansions is a reduced genetic diversity due to founder effects (Slatkin \& Excoffier, 2012). However, hybridization and introgression with a locally adapted resident species during the range expansion process can be a counterforce that increases overall genetic diversity and/or specific alleles (Behm, Ives, \& Boughman, 2010; Mehner et al., 2010; Pfennig, Kelly, \& Pierce, 2016; Rieseberg et al., 2007). Introgressive hybridization during the range expansion of I. elegans in Spain can be a source of new alleles to recently expanded populations in the Spanish hybrid region. It appears that the range expansion has coincided with the hybridization of I. elegans in Spain, and this has not only prevented the loss of ge- 
netic diversity in both hybrid regions, but also increased diversity in the north-west hybrid region. Further, consistent with theoretical expectations, hybridization also resulted in reduced interspecific differentiation in sympatry, i.e., genetic differentiation betweenI. elegans and I. graellsii was lower in the sympatric than in the allopatric distribution. Dudaniec et al. (2018) investigated neutral and adaptive molecular signatures along the northward range expansion axis of I. elegans in where no other Ischnuraspp. occur. Interestingly, also no decrease in genetic diversity along this axis was found; and observed heterozygosity was similar between core and range-expanded populations, even without hybridization opportunities. Another study investigating the genetic consequences of northern range expansion in damselflies did, however, report small genetic diversity losses in recently established populations (Swaegers et al., 2015). Due to introgression, I. elegans and $I$. graellsii populations showed slightly lower overall genetic differentiation in sympatry (mean=0.691) than in allopatry (mean=0.725), similar to patterns detected in other taxa (e.g., Anderson \& Hubricht, 1938; Fu, Lu, Fu, \& Wang, 2020). Demographic processes associated with range expansions, such as repeated bottlenecks and genetic drift can also increase the level of differentiation between species (Freedman, Thomassen, Buermann, \& Smith, 2010; Wang, Abbott, Ingvarsson, \& Liu, 2014). This may have contributed to the high and significantly observed pairwise genetic differentiation between $I$. elegans and I. graellsii in the north-west hybrid region respect to the north-central and the allopatric regions. In summary, the higher level of genetic divergence and genetic differentiation detected in the north-west hybrid region can be explained by local demographic processes (bottlenecks and genetic drift) and the time since the colonization.

\section{Conclusions}

Studies examining the evolutionary outcomes of hybridization along space and time are necessary to understand whether hybridization outcomes represent general patterns or are species and context specific. In this study, we provide evidence for on-going hybridization and bidirectional backcrosses, with different admixtureclass distributions in different damselfly hybrid regions which may in part be explained by 1) proximity to introduction site, 2) local dynamics, 3) the strength of reproductive barriers, and 4) the time elapsed since colonization. We also provide evidence of increased genetic diversity and reduced genetic differentiation in a range expansion when opportunities for hybridization occur.

\section{ACKNOWLEDGEMENTS}

We are very grateful to Adolfo Cordero Rivera, who kindly allowed us to use his laboratory and material for the rearing experiments, and to Zalandrana Odonatology group who kindly help us with samplings and permissions in north-central Spain. We thank the following colleagues for kindly helping with collecting/sending samples: Adolfo Cordero Rivera, Iñaki Mezquita, Mario García-París, Bernat Garriós, Pere Luque, Xoaquín Baixeras, Francisco Cano, Jean Pierre Boudot, Jürgen Ott, Cedrick Vanappelghem, Philippe Lambret, and Phill Watts. We are grateful to Janet Nolasco Soto and Emmanuel Villafán de la Torre for technical support. Sequencing was performed by BGI (Hongkong) and the SNP\&SEQ Technology Platform in Uppsala, which is part of the National Genomics Infrastructure (NGI) Sweden and Science for Life Laboratory, supported by the Swedish Research Council and the Knut and Alice Wallenberg Foundation. Bioinformatics analyses were performed on resources provided by the Swedish National Infrastructure for Computing (SNIC) at Uppsala Multidisciplinary Center for Advanced Computational Science (UPPMAX) and the Huitzilin 2.0 HPC system at the Instituto de Ecología A.C (INECOL). The research was funded by the Karl-Tryggers Foundation (to RAS-G and MW), the Kungl. Vetenskapsakademien (BS2015-0001 to RAS-G), the Royal Physiological Society in Lund (the Nilsson-Ehle Foundation, 36118 to RAS-G, and 37369 to MW), the Swedish Research Council (621-2016-689 to BH) the Marie Curie Intraeuropean Fellowship (to JS, RAS-G, MW and BH), and from Mexican CONACYT (282922 to RAS-G).

\section{AUTHORS' CONTRIBUTIONS}

RAS-G, MW and BH conceived the study idea. RAS-G, LRA-V and JS performed analyses. RAS-G, MW and $\mathrm{BH}$ wrote the first draft which was then edited by all co-authors.

\section{DATA ACCESSIBILITY}


All data files, as well as the scripts for the full pipeline analyses are deposited on OSF at:

https://osf.io/5kg87/?view_only=438667bce73d41ecab7137a65c625ded

REFERENCES

Abbott, R., Albach, D., Ansell, S., Arntzen, J. W., Baird, S. J. E., Bierne, N., ... Zinner, D. (2013). Hybridization and speciation. Journal of Evolutionary Biology , 26 (2), 229-246. doi: 10.1111/j.14209101.2012.02599.x

Aboim, M. A., Mavárez, J., Bernatchez, L., \& Coelho, M. M. (2010). Introgressive hybridization between two Iberian endemic cyprinid fish: A comparison between two independent hybrid zones. Journal of Evolutionary Biology , 23 (4), 817-828. doi: 10.1111/j.1420-9101.2010.01953.x

Alexander, D. H., \& Lange, K. (2011). Enhancements to the ADMIXTURE algorithm for individual ancestry estimation. BMC Bioinformatics ,12 (1), 246. doi: 10.1186/1471-2105-12-246

Anderson, E., \& Hubricht, L. (1938). Hybridization in Tradescantia. III. The Evidence for Introgressive Hybridization. American Journal of Botany . doi: 10.2307/2436413

Arce-Valdés, R., Ballén-Guapacha, A., \& Sánchez-Guillén, R. (n.d.). Rapid reinforcement of premating isolation in a damselfly hybrid region.Submitted Manuscrript .

Askew, R. (1989). The Dragonflies of Europe (B. H. \& A. Harley, Ed.). Colchester, England: Harley Books. doi: 10.1002/iroh.19890740432

Behm, J. E., Ives, A. R., \& Boughman, J. W. (2010). Breakdown in postmating isolation and the collapse of a species pair through hybridization. American Naturalist , 175 (1), 11-26. doi: 10.1086/648559

Boudot, J. P., Kalkman, V. J., Azpilicueta-Amorín, M., Bogdanovic, T., Dommanget, L., Ferreira, S., ... Schneider, W. (2009). Odonata of the Mediterranean and North Africa. Libellula Supplement ,9 , 1-256.

Buerkle, C. A. (2005). Maximum-likelihood estimation of a hybrid index based on molecular markers. Molecular Ecology Notes , 5 , 684-687. doi: 10.1111/j.1471-8286.2005.01011.x

Buerkle, C. A., \& Rieseberg, L. H. (2001). Low intraspecific variation for genomic isolation between hybridizing sunflower species.Evolution , 55 (4), 684-695. doi: 10.1554/0014-3820(2001)055[0684:livfgi]2.0.co;2

Catchen, J., Hohenlohe, P. A., Bassham, S., Amores, A., \& Cresko, W. A. (2013). Stacks: An analysis tool set for population genomics. Molecular Ecology ,22 (11), 3124-3140. doi: 10.1111/mec.12354

Catchen, J. M., Amores, A., Hohenlohe, P., Cresko, W., \& Postlethwait, J. H. (2011). Stacks: Building and genotyping loci de novo from short-read sequences. G3: Genes, Genomes, Genetics , 1 (3), 171-182. doi: $10.1534 / \mathrm{g} 3.111 .000240$

Chauhan, P., Swaegers, J., Sánchez-Guillén, R. A., Svensson, E. I., Wellenreuther, M., \& Hansson, B. (2021). Genome assembly, sex-biased gene expression and dosage compensation in the damselfly Ischnura elegans. Genomics , 113 (4), 1828-1837. doi: 10.1016/j.ygeno.2021.04.003

Coyne, J. A. \& O. (2004). Speciation. Sunderland, MA: Sinauer Associates .

Danecek, P., Auton, A., Abecasis, G., Albers, C. A., Banks, E., DePristo, M. A., ... Durbin, R. (2011). The variant call format and VCFtools. Bioinformatics , 27 (15), 2156-2158. doi: 10.1093/bioinformatics/btr330

Dijkstra, K. D. B., \& Kalkman, V. J. (2012). Phylogeny, classification and taxonomy of European dragonflies and damselflies (Odonata): A review. Organisms Diversity and Evolution , 12 (3), 209-227. doi: 10.1007/s13127-012-0080-8

Dudaniec, R. Y., Yong, C. J., Lancaster, L. T., Svensson, E. I., \& Hansson, B. (2018). Signatures of local adaptation along environmental gradients in a range-expanding damselfly (Ischnura elegans).Molecular Ecology , 27 (11), 2576-2593. doi: 10.1111/mec.14709 
Etter, P. D., Bassham, S., Hohenlohe, P. A., Johnson, E. A., \& Cresko, W. A. (2011). SNP discovery and genotyping for evolutionary genetics using RAD sequencing. Methods in Molecular Biology (Clifton, N.J.), 772, $157-178$.

Fitzpatrick, B. M. (2012). Estimating ancestry and heterozygosity of hybrids using molecular markers. BMC Evolutionary Biology ,12 (1), 131. doi: 10.1186/1471-2148-12-131

Freedman, A. H., Thomassen, H. A., Buermann, W., \& Smith, T. B. (2010). Genomic signals of diversification along ecological gradients in a tropical lizard. Molecular Ecology , 19 (17), 3773-3788. doi: 10.1111/j.1365294X.2010.04684.x

Fu, Q., Lu, G. H., Fu, Y. H., \& Wang, Y. Q. (2020). Genetic differentiation between two varieties of Oreocharis benthamii (Gesneriaceae) in sympatric and allopatric regions. Ecology and Evolution , 10 (14), 7792-7805. doi: $10.1002 /$ ece3.6505

Gompert, Z., \& Alex Buerkle, C. (2010). Introgress: A software package for mapping components of isolation in hybrids. Molecular Ecology Resources , 10 (2), 378-384. doi: 10.1111/j.1755-0998.2009.02733.x

Gompert, Z., Lucas, L. K., Buerkle, C. A., Forister, M. L., Fordyce, J. A., \& Nice, C. C. (2014). Admixture and the organization of genetic diversity in a butterfly species complex revealed through common and rare genetic variants. Molecular Ecology , 23 (18), 4555-4573. doi: 10.1111/mec.12811

Gompert, Z., Mandeville, E. G., \& Buerkle, C. A. (2017). Analysis of Population Genomic Data from Hybrid Zones. Annual Review of Ecology, Evolution, and Systematics , 48 (1), 207-229. doi: 10.1146/annurev-ecolsys110316-022652

González-Tokman, D., Córdoba-Aguilar, A., Dáttilo, W., Lira-Noriega, A., Sánchez-Guillén, R. A., \& Villalobos, F. (2020). Insect responses to heat: physiological mechanisms, evolution and ecological implications in a warming world. Biological Reviews , 95 (3), 802-821. doi: 10.1111/brv.12588

Good, J. M., Handel, M. A., \& Nachman, M. W. (2008). Asymmetry and polymorphism of hybrid male sterility during the early stages of speciation in house mice. Evolution , 62 (1), 50-65. doi: 10.1111/j.15585646.2007.00257.x

Goudet, J. (2005). HIERFSTAT, a package for R to compute and test hierarchical F-statistics. Molecular Ecology Notes , 5 (1), 184-186. doi: 10.1111/j.1471-8286.2004.00828.x

Graffelman, J., \& Moreno, V. (2013). The mid p-value in exact tests for Hardy-Weinberg equilibrium. Statistical Applications in Genetics and Molecular Biology , 12 (4), 433-448. doi: 10.1515/sagmb-2012-0039

Harrison, R. G., \& Bogdanowicz, S. M. (1997). Patterns of variation and linkage disequilibrium in a field cricket hybrid zone. Evolution ,51 (2), 493-505. doi: 10.1111/j.1558-5646.1997.tb02437.x

Harrison, R. G., \& Larson, E. L. (2016). Heterogeneous genome divergence, differential introgression, and the origin and structure of hybrid zones. Molecular Ecology , 25 (11), 2454-2466. doi: 10.1111/mec.13582

Haselhorst, M. S. H., \& Buerkle, C. A. (2013). Population genetic structure of Picea engelmannii, P. glauca and their previously unrecognized hybrids in the central Rocky Mountains. Tree Genetics and Genomes , 9 , 669-681. doi: 10.1007/s11295-012-0583-7

Hassall, \& Thompson, D. J. (2008). The effects of environmental warming on Odonata : a review. International Journal of Odonatology ,11 (2), 131-153.

Hassall, Thompson, D. J., \& French, G. C. (2007). Historical changes in the phenology of British Odonata are related to climate. Global Change Biology, 13 (5), 933-941.

Hickling, R., Roy, D. B., Hill, K., \& Thomas, C. D. (2005). A northward shift of range margins in British Odonata. Global Change Biology ,11, 502-506. 
Hohenlohe, P. A., Amish, S. J., Catchen, J. M., Allendorf, F. W., \& Luikart, G. (2011). Next-generation RAD sequencing identifies thousands of SNPs for assessing hybridization between rainbow and westslope cutthroat trout. Molecular Ecology Resources , 11 (S1), 117-122.

Jiggins, C. D., \& Mallet, J. (2000). Bimodal hybrid zones and speciation. Trends in Ecology and Evolution , 15 (6), 250-255. doi: 10.1016/S0169-5347(00)01873-5

Jordan, C. Y., Lohse, K., Turner, F., Thomson, M., Gharbi, K., \& Ennos, R. A. (2018). Maintaining their genetic distance: Little evidence for introgression between widely hybridizing species of Geum with contrasting mating systems. Molecular Ecology , 27 (5), 1214-1228. doi: 10.1111/mec.14426

Kronforst, M. R., Young, L. G., \& Gilbert, L. E. (2007). Reinforcement of mate preference among hybridizing Heliconius butterflies. Journal of Evolutionary Biology , 20 (1), 278-285. doi: 10.1111/j.14209101.2006.01198.x

Lancaster, L. T., Dudaniec, R. Y., Chauhan, P., Wellenreuther, M., Svensson, E. I., \& Hansson, B. (2016). Gene expression under thermal stress varies across a geographical range expansion front. Molecular Ecology , 25 (5), 1141-1156. doi: 10.1111/mec.13548

Langmead, B., \& Salzberg, S. L. (2012). Fast gapped-read alignment with Bowtie 2. Nature Methods , 9 (4), 357-359. doi: 10.1038/nmeth.1923

Larson, E. L., White, T. A., Ross, C. L., \& Harrison, R. G. (2014). Gene flow and the maintenance of species boundaries. Molecular Ecology, 23 (7), 1668-1678. doi: 10.1111/mec.12601

Lemmon, E. M., \& Juenger, T. E. (2017). Geographic variation in hybridization across a reinforcement contact zone of chorus frogs (Pseudacris). Ecology and Evolution, 7 (22), 9485-9502. doi: 10.1002/ece3.3443

Leong, J. M., \& Hafernik, J. E. J. (1992). Hybridization between two damselfly species (Odonata: Coenagrionidae: morphometric and genitalic differentiation. Entomological Society of America , 85 (6), 662-670.

Lepais, O., Petit, R. J., Guichoux, E., Lavabre, J. E., Alberto, F., Kremer, A., \& Gerber, S. (2009). Species relative abundance and direction of introgression in oaks. Molecular Ecology ,18 (10), 2228-2242. doi: 10.1111/j.1365-294X.2009.04137.x

Liao, W. J., Zhu, B. R., Li, Y. F., Li, X. M., Zeng, Y. F., \& Zhang, D. Y. (2019). A comparison of reproductive isolation between two closely related oak species in zones of recent and ancient secondary contact.BMC Evolutionary Biology , 19 (1), 1-10. doi: 10.1186/s12862-019-1399-y

Mandeville, E. G., Parchman, T. L., Thompson, K. G., Compton, R. I., Gelwicks, K. R., Song, S. J., \& Buerkle, C. A. (2017). Inconsistent reproductive isolation revealed by interactions between Catostomus fish species. Evolution Letters , 1 (5), 255-268. doi: 10.1002/evl3.29

Mehner, T., Pohlmann, K., Elkin, C., Monaghan, M. T., Nitz, B., \& Freyhof, J. (2010). Genetic population structure of sympatric and allopatric populations of Baltic ciscoes (Coregonus albula complex, Teleostei, Coregonidae). BMC Evolutionary Biology , 10 (1), 85. doi: 10.1186/1471-2148-10-85

Milne, R. I., \& Abbott, R. J. (2008). Reproductive isolation among two interfertile Rhododendron species: Low frequency of post-F1 hybrid genotypes in alpine hybrid zones. Molecular Ecology ,17 (4), 1108-1121. doi: 10.1111/j.1365-294X.2007.03643.x

Monetti, L., Sanchez-Guillen, R. A., \& Cordero Rivera, A. (2002). Hybridization between Ischnura graellsii (Vander Linder) and I. elegans (Rambur) (Odonata: Coenagrionidae): Are they different species? Biological Journal of the Linnean Society, 76 (2), 225-235.

Nolte, A. W., Gompert, Z., \& Buerkle, C. A. (2009). Variable patterns of introgression in two sculpin hybrid zones suggest that genomic isolation differs among populations. Molecular Ecology ,18 (12), 2615-2627. doi: 10.1111/j.1365-294X.2009.04208.x 
Ocharan, F. J. (1987). Los odonatos de Asturias y de Espana: aspectos sistematicos y faunisticos (Thesis Universidad de Oviedo; Vol. 83). Thesis Universidad de Oviedo. Retrieved from c:\%5CRevistas\%5CTesis\%5COcharan 1987 Tesis Odonatos Ast y Esp.pdf

Ott, J. (2010). The big trek northwards: recent changes in the european dragonfly fauna. In J. Settele, L. L. Penrev, T. Grabaum, V. Grobelink, V. Hammen, S. Klotz, ... I. Kuhn (Eds.), Atlas of biodiversity risk (pp. 82-83). Pensoft, Publishers.

Pembleton, L. W., Cogan, N. O. I., \& Forster, J. W. (2013). StAMPP: An R package for calculation of genetic differentiation and structure of mixed-ploidy level populations. Molecular Ecology Resources ,13 (5), 946-952. doi: 10.1111/1755-0998.12129

Pfennig, K. S., Kelly, A. L., \& Pierce, A. A. (2016). Hybridization as a facilitator of species range expansion. Proceedings. Biological Sciences , 283 (1839), 1329. doi: 10.1098/rspb.2016.1329

Purcell, S., Neale, B., Todd-Brown, K., Thomas, L., Ferreira, M. A. R., Bender, D., .. Sham, P. C. (2007). PLINK: A tool set for whole-genome association and population-based linkage analyses.American Journal of Human Genetics , 81 (3), 559-571. doi: 10.1086/519795

R Core Team. (2016). R: A language and environment for statistical computing. R Foundation for Statistical Computing, Viena, Austria .

Rieseberg, L. H., Kim, S. C. S.-C. S. C., Randell, R. A., Whitney, K. D., Gross, B. L., Lexer, C., \& Clay, K. (2007). Hybridization and the colonization of novel habitats by annual sunflowers. Genetica ,129 (2), 149-165. doi: 10.1007/s10709-006-9011-y

Sanchez-Guillen, Munoz, J., Rodriguez-Tapia, G., Arroyo, T. P. F., \& Cordoba-Aguilar, A. (2013). Climateinduced range shifts and possible hybridisation consequences in insects. PLoS ONE , 8 (11), 1-10. doi: 10.1371/journal.pone.0080531

Sanchez-Guillen, R. A., Cordoba-Aguilar, A., Cordero-Rivera, A., \& Wellenreuther, M. (2014). Genetic divergence predicts reproductive isolation in damselflies. Journal of Evolutionary Biology ,27 (1), 76-87.

Sanchez-Guillen, R. A., Fadia-Ceccarelli, S., Villalobos, F., Neupane, S., Rivas-Torres, A., Sanmartin-Villar, I., ... Cordero-Rivera, A. (2020). The evolutionary history of colour polymorphism in Ischnura damselflies (Odonata: Coenagrionidae). Odonatologica ,49 (3), 333-370. doi: 10.1111/jeb.13289

Sanchez-Guillen, R. A., Munoz, J., Hafernik, J., Tierney, M., Rodriguez-Tapia, G., \& Cordoba-Aguilar, A. (2014). Hybridization rate and climate change: Are endangered species at risk? Journal of Insect Conservation , 18 (3), 295-305. doi: 10.1007/s10841-014-9637-5

Sanchez-Guillen, R. A., van Gossum, H., \& Cordero-Rivera, A. (2005). Hybrization and the inheritance of female colour polymorphism in two ischnuran damselflies (Odonata : Coenagrionidae). Biological Journal of the Linnean Society , 85 (4), 471-481. doi: 10.1111/j.1095-8312.2005.00506.x

Sanchez-Guillen, R. A., Van Gossum, H., \& Cordero Rivera, A. (2005). Hybridization and the inheritance of female colour polymorphism in two ischnurid damselflies (Odonata: Coenagrionidae). Biological Journal of the Linnean Society , 85 (4), 471-482.

Sanchez-Guillen, R. A., Wellenreuther, M., \& Cordero-Rivera, A. (2011). Strong asymmetry in the relative strengths of prezygotic and postzygotic barriers between two damselfly sister species. Evolution ,66 (3), 690-707.

Sanchez-Guillen, R a, Cordoba-Aguilar, A., Cordero-Rivera, A., \& Wellenreuther, M. (2014). Rapid evolution of prezygotic barriers in polymorphic damselflies. Biological Journal of the Linnean Society , 27 , 76-87. doi: $10.1111 /$ bij.12347

Sanchez-Guillen, Rosa, Cordoba-Aguilar, A., Hansson, B., Ott, J., \& Wellenreuther, M. (2016). Evolutionary consequences of climate-induced range shifts in insects. Biological Reviews , 91 (4), 1050-1064. doi: 


\section{$10.1111 /$ brv. 12204}

Sanchez-Guillen, Wellenreuther, M., \& Cordero-Rivera, A. (2012). Strong asymmetry in the relative strengths of prezygotic and postzygotic barriers between two damselfly sister species. Evolution ,66 (3), 690-707.

Sanchez-Guillen, Wellenreuther, M., Cordero-Rivera, A., \& Hansson, B. (2011). Introgression and rapid species turnover in sympatric damselflies. BMC Evolutionary Biology, 11 (1), 210. doi: 10.1186/1471-2148$11-210$

Seehausen, O. (2004). Hybridization and adaptive radiation. Trends in Ecology and Evolution , 19 (4), 198-207. doi: $10.1016 /$ j.tree.2004.01.003

Slatkin, M., \& Excoffier, L. (2012). Serial founder effects during range expansion: A spatial analog of genetic drift. Genetics ,191 (1), 171-181. doi: 10.1534/genetics.112.139022

Stankowski, S., Westram, A. M., Zagrodzka, Z. B., Eyres, I., Broquet, T., Johannesson, K., \& Butlin, R. K. (2020). The evolution of strong reproductive isolation between sympatric intertidal snails: Strong RI in Littorinids. Philosophical Transactions of the Royal Society B: Biological Sciences , 375 (1806). doi: 10.1098/rstb.2019.0545

Swaegers, J., Mergeay, J., Van Geystelen, A., Therry, L., Larmuseau, M. H. D., \& Stoks, R. (2015). Neutral and adaptive genomic signatures of rapid poleward range expansion. Molecular Ecology, 24 (24), 6163-6176. doi: $10.1111 /$ mec.13462

Sweigart, A. L., Mason, A. R., \& Willis, J. H. (2007). Natural variation for a hybrid incompatibility between two species of mimulus: Original article. Evolution , 61 (1), 141-151. doi: 10.1111/j.1558-5646.2007.00011.x

Szymura, J. M., \& Barton, N. H. (1991). The genetic structure of the hybrid zone between the fire-bellied toads Bombina bombina and B. variegata: comparisons between transects and between loci.Evolution , 45 (2), 237-261. doi: 10.1111/j.1558-5646.1991.tb04400.x

Todesco, M., Pascual, M. A., Owens, G. L., Ostevik, K. L., Moyers, B. T., Hubner, S., .. Rieseberg, L. H. (2016). Hybridization and extinction. Evolutionary Applications , 9 (7), 892-908. doi: 10.1111/eva.12367

Vines, T. H., Kohler, S. C., Thiel, M., Ghira, I., Sands, T. R., MacCallum, C. J., .. N Nurnberger, B. (2003). The Maintenance of Reproductive Isolation in a Mosaic Hybrid Zone Between the Fire-Bellied Toads Bombina Bombina and B. Variegata. Evolution , 57 (8), 1876-1888. doi: 10.1111/j.0014-3820.2003.tb00595.x

Walsh, J., Shriver, W. G., Olsen, B. J., O’Brien, K. M., \& Kovach, A. I. (2015). Relationship of phenotypic variation and genetic admixture in the Saltmarsh-Nelson's sparrow hybrid zone. Auk, 132 (3), 704-716. doi: 10.1642/AUK-14-299.1

Wang, J., Abbott, R. J., Ingvarsson, P. K., \& Liu, J. (2014). Increased genetic divergence between two closely related fir species in areas of range overlap. Ecology and Evolution , 4 (7), 1019-1029. doi: 10.1002/ece3.1007

Wellenreuther, M., Munoz, J., Chavez-Rios, J. R., Hansson, B., Cordero-Rivera, A., \& Sanchez-Guillen, R. A. (2018). Molecular and ecological signatures of an expanding hybrid zone. Ecology and Evolution, 8 (10), 4793-4806. doi: 10.1002/ece3.4024

Wellenreuther, M., \& Sanchez-Guillen, R. A. R. (2015). Nonadaptive radiation in damselflies. Evolutionary Applications , 9 (1), 103-118. doi: 10.1111/eva.12269

Zheng, X., Levine, D., Shen, J., Gogarten, S. M., Laurie, C., \& Weir, B. S. (2012). A high-performance computing toolset for relatedness and principal component analysis of SNP data. Bioinformatics ,28 (4), 3326-3328. doi: 10.1093/bioinformatics/bts606

Table 1. Species, sampling locality and country, sample size for molecular analysis $(\mathrm{N})$ indicates the number of morphologically identified samples (I. elegans -like (I. e) and I. graellsii -like (I. g), ecology, sampling year, 
latitude/longitude.

Region

Allopatry

North-central hybrid region

Norh-west hybrid region

North-east Spain (Menorca)

Two samples removed after SNP calling due to possible hybridization with a third unknown species. ${ }^{+}$ADMIXTURE anal

Table 2. Local dynamics.Hybrid region, population locality, first (older) data of the species at the population, year when the population was colonized by a second species (I. elegans in the case of previously I. graellsiipopulations, or I. graellsii in the case of previously I. elegans populations), recolonization of the population because of desiccation by management of invasive species or natural causes, current dominant species, molecular population data.

\begin{tabular}{|c|c|c|c|c|c|c|}
\hline $\begin{array}{l}\text { Hybrid } \\
\text { Region }\end{array}$ & Locality & $\begin{array}{l}\text { Oldest } \\
\text { data }\end{array}$ & Colonization & Recolonization & $\begin{array}{l}\text { Current } \\
\text { dominant } \\
\text { species }\end{array}$ & $\begin{array}{l}\text { Molecular } \\
\text { data }\end{array}$ \\
\hline \multirow[t]{5}{*}{$\begin{array}{l}\text { North-central } \\
\text { Spain }\end{array}$} & Mateo & $\begin{array}{l}2015, \text { only } I . \\
\text { graellsii }\end{array}$ & $\begin{array}{l}2016, I . \\
\text { graellsii, } \\
\text { occasionally } I . \\
\text { elegans }\end{array}$ & $\begin{array}{l}2017 \text { (dried), } \\
\text { both species }\end{array}$ & $\begin{array}{l}2018, I . \\
\text { graellsii, } \\
\text { occasionally } I . \\
\text { elegans }\end{array}$ & 2015 \\
\hline & Valpierre & $\begin{array}{l}2008, \text { only } I . \\
\text { graellsii }\end{array}$ & $\begin{array}{l}2016, I . \\
\text { graellsii, } \\
\text { occasionally } \\
\text { I. eleaans }\end{array}$ & & $\begin{array}{l}2017-2018, \text { I. } \\
\text { graellsii, } \\
\text { occasionally } \\
\text { I. elegans }\end{array}$ & 2015 \\
\hline & Villar & $\begin{array}{l}2008, \text { both } \\
\text { species }\end{array}$ & & & $\begin{array}{l}2015-2018 \\
\text { both species }\end{array}$ & 2015 \\
\hline & Arreo & $\begin{array}{l}2008, \text { both } \\
\text { species }\end{array}$ & & & $\begin{array}{l}2008-2015 \\
\text { both species }\end{array}$ & 2008 \\
\hline & Perdiguero & $\begin{array}{l}2008, \text { both } \\
\text { species }\end{array}$ & & & $\begin{array}{l}2015-2018, \\
\text { both species }\end{array}$ & 2015 \\
\hline
\end{tabular}




\begin{tabular}{|c|c|c|c|c|c|c|}
\hline $\begin{array}{l}\text { Hybrid } \\
\text { Region }\end{array}$ & Locality & $\begin{array}{l}\text { Oldest } \\
\text { data }\end{array}$ & Colonization & Recolonization & $\begin{array}{l}\text { Current } \\
\text { dominant } \\
\text { species }\end{array}$ & $\begin{array}{l}\text { Molecular } \\
\text { data }\end{array}$ \\
\hline \multirow{6}{*}{$\begin{array}{l}\text { North-west } \\
\text { Spain }\end{array}$} & Las Cañas & $\begin{array}{l}2007, \text { both } \\
\text { species }\end{array}$ & \multirow{6}{*}{$\begin{array}{l}2003, I . \\
\text { graellsii, } \\
\text { occasionally } I . \\
\text { elegans }\end{array}$} & \multirow[t]{3}{*}{$\begin{array}{l}2012 \text { (dried), } \\
\text { both species }\end{array}$} & $\begin{array}{l}2015-2017 \\
\text { both species }\end{array}$ & 2015 \\
\hline & Valbornedo & $\begin{array}{l}2008, I . \\
\text { elegans }\end{array}$ & & & $\begin{array}{l}2015-2018, \\
\text { both species }\end{array}$ & 2015 \\
\hline & Doniños & $\begin{array}{l}\text { 1987, only } I . \\
\text { elegans }\end{array}$ & & & $\begin{array}{l}\text { 1987-2021, I. } \\
\text { elegans } \\
\text { occasionally } \\
\text { I. graellsii }\end{array}$ & 2014 \\
\hline & Laxe & $\begin{array}{l}2000 \text {, only } I . \\
\text { elegans }\end{array}$ & & \multirow[t]{2}{*}{$\begin{array}{l}2000 \text { (dried), } \\
\text { I. elegans }\end{array}$} & $\begin{array}{l}\text { 2001-2021, I. } \\
\text { elegans, } \\
\text { occasionally } I . \\
\text { graellsii }\end{array}$ & 2014 \\
\hline & Xuño & $\begin{array}{l}2001 \text {, only } I \text {. } \\
\text { graellsii }\end{array}$ & & & $\begin{array}{l}2004-2006, \\
\text { both species } \\
2007-2021, \\
\text { only } I . \\
\text { graellsii }\end{array}$ & 2014 \\
\hline & Louro & $\begin{array}{l}\text { 1980, both } \\
\text { species }\end{array}$ & & $\begin{array}{l}2010 \\
\text { (brackish } \\
\text { water), I. } \\
\text { graellsii, } \\
\text { occasionally } \\
\text { I. elegans }\end{array}$ & $\begin{array}{l}2013-2021, I . \\
\text { graellsii, } \\
\text { occasionally } \\
\text { I. elegans }\end{array}$ & 2013 \\
\hline
\end{tabular}

Note: Cañas in 2012 and Mateo in 2017, were desiccated by management of invasive species (mainly American crab) and by use of water for irrigation, respectively. Laxe in 2000 was naturally desiccated (evaporation), and Louro (retro dune lagoon) in 2010 suffered a brackish water event.

Table 3. Distribution of individuals in eight ranges of HI/HET resulting from Introgressed. North-central Spain included 68 samples (33I. elegans -like and 35 I. graellsii -like) and north-west included 40 samples (21 I. elegans -like and 19 I. graellsii -like. All hybrids $\left(\mathrm{F}_{1}\right.$ and $\left.\mathrm{F}_{2}\right)$ were a priori, morphologically identified as I. graellsii, which is consistent with the morphology of the $\mathrm{F}_{1}$ and $\mathrm{F}_{2}$ hybrids from the laboratory (Monetti et al., 2002; R. A. Sánchez-Guillén et al., 2005) which usually resemble I. graellsii individuals.

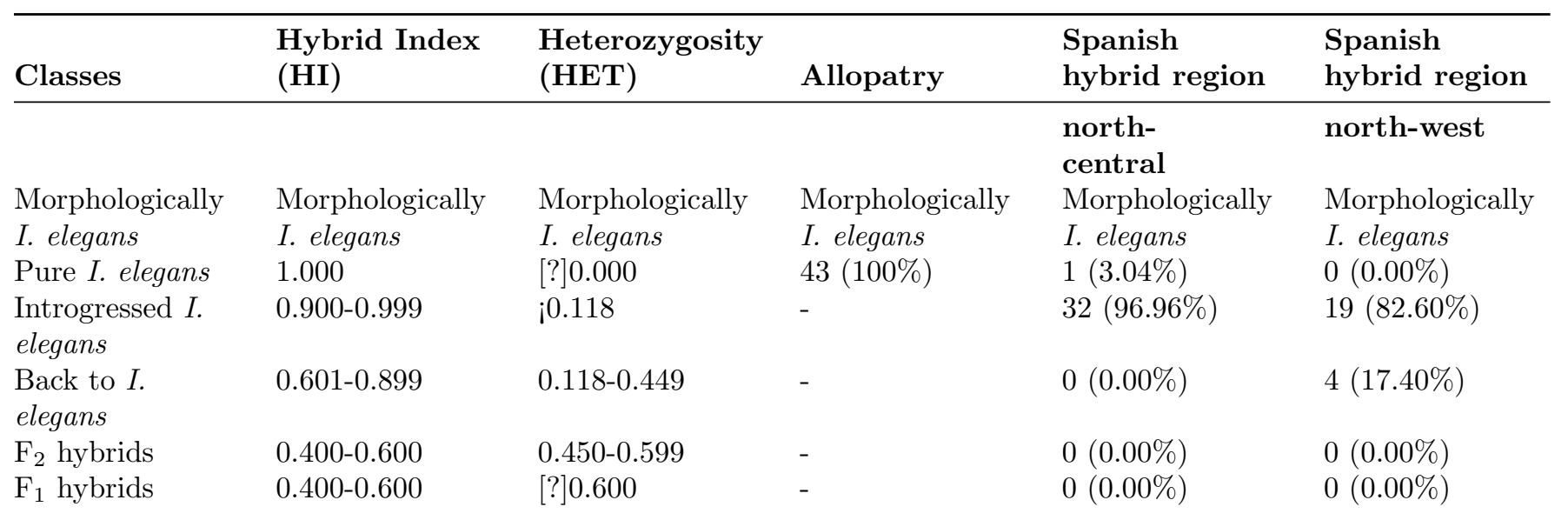




\begin{tabular}{|c|c|c|c|c|c|}
\hline Classes & $\begin{array}{l}\text { Hybrid Index } \\
\text { (HI) }\end{array}$ & $\begin{array}{l}\text { Heterozygosity } \\
\text { (HET) }\end{array}$ & Allopatry & $\begin{array}{l}\text { Spanish } \\
\text { hybrid region }\end{array}$ & $\begin{array}{l}\text { Spanish } \\
\text { hybrid region }\end{array}$ \\
\hline Morphologically & Morphologically & Morphologically & Morphologically & Morphologically & Morphologically \\
\hline I. graellsii & I. graellsii & I. graellsii & I. graellsii & I. graellsii & I. graellsii \\
\hline $\begin{array}{l}\text { Pure } I . \\
\text { graellsii }\end{array}$ & 0.000 & {$[?] 0.000$} & $25(100 \%)$ & $1(2.86 \%)$ & $0(0.00 \%)$ \\
\hline $\begin{array}{l}\text { Introgressed } I . \\
\text { graellsii }\end{array}$ & $0.001-0.100$ & ¡0.118 & - & $27(77.14 \%)$ & $10(58.82 \%)$ \\
\hline $\begin{array}{l}\text { Back to } I \\
\text { graellsii }\end{array}$ & 0.101-0.399 & $0.118-0.449$ & - & $3(8.57 \%)$ & $2(11.76 \%)$ \\
\hline $\mathrm{F}_{2}$ hybrids & $0.400-0.600$ & $0.450-0.599$ & - & $0(0.00 \%)$ & $2(11.76 \%)$ \\
\hline $\mathrm{F}_{1}$ hybrids & $0.400-0.600$ & {$[?] 0.600$} & - & $4(11.43 \%)$ & $3(17.65 \%)$ \\
\hline
\end{tabular}

\section{Figure Legends}

Figure 1. Studied hybrid region. A) Map of the 20 sampled populations. Dark blue circles denote allopatric I. elegans, yellow circles denote allopatric I. graellsii . Inside of the Spanish hybrid region, dark blue, yellow and orange circles denote $I$. elegans dominant, I. graellsii dominant or both species, respectively (1 indicates north-west populations, 2 indicates north-central populations and 3 the Balearic population). B)Zoom of Spain, showing the geographic distribution of I. elegans over time, from 1888-1979 (8 provinces, dark-grey), 1980-1999 (13 provinces, medium grey) and 2000-actuality (12 provinces, light grey). White colour indicates onlyI. graellsii populations (15 provinces).

Figure 2. Strength of mechanical barriers to reach the copula in $\mathbf{A}$ ) north-central hybrid region (colonized by $I$. elegans at least 14 years ago), and B) north-western hybrid region (colonized by I. elegans at least 41 years ago). INTROGRESS estimates of ancestry proportion (HI) and heterospecific ancestry (HET) by using the 381 fixed SNPs for I. elegans, I. graellsii and hybrids fromC ) north-central hybrid region and D ) north-western hybrid region. $\mathrm{F}_{1}$ and $\mathrm{F}_{2}$ hybrids (orange) occupy the apex of the triangle. Backcrosses to I. elegans introgressed I. elegans and pure I. elegans(light blue). Backcrosses to I. graellsii, introgressed $I$. graellsii and pure I. graellsii (light blue).

Figure 3 . INTROGRESS individual and class proportions estimates of ancestry proportion in $\mathbf{A}$ ) northcentral hybrid populations, and B) north-west hybrid populations. Populations were assigned to three qualitative measures depending on the frequency distribution of the different hybrid classes: unimodal hybridization pattern, when the distribution spans a range of admixture and backcrosses towards both parental species; bimodal hybridization pattern, when the distribution is deviated to the two parental or parentallike genotypes, and few hybrids ( $\mathrm{F}_{1}$ and $\mathrm{F}_{2}$ hybrids); and introgressed hybridization pattern, when the distribution was deviated to one parental-like genotype.

Figure 4. Heterozygosity violin plot by population. A ) I. elegans without hybrids, B ) I. elegans with hybrids, C )I. graellsii with hybrids, D ) I. graellsiiwithout hybrids. Violin width represents the relative frequency of SNPs at each observed heterozygosity value, i.e., wider violin areas show higher number of SNPs at that heterozygosity. The line and the circle at each violin represents the median and the average $\mathrm{H}_{\mathrm{O}}$, while the triangle points at the average $\mathrm{H}_{\mathrm{E}}$. Finally, the value above each violin shows the percentages of SNPs that showed statistical differences between $\mathrm{H}_{\mathrm{O}}$ and $\mathrm{H}_{\mathrm{E}}(\mathrm{p}<0.05)$ to the total number of non-missing-data SNPs. 
A.

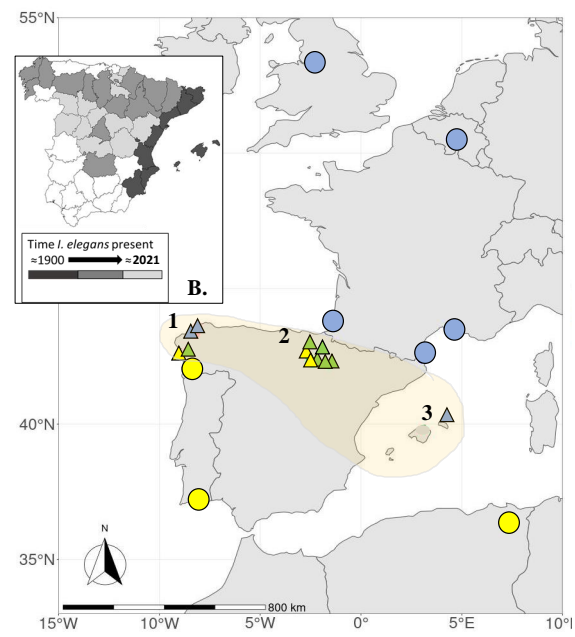

A. North-central Spain $>15$ years ago

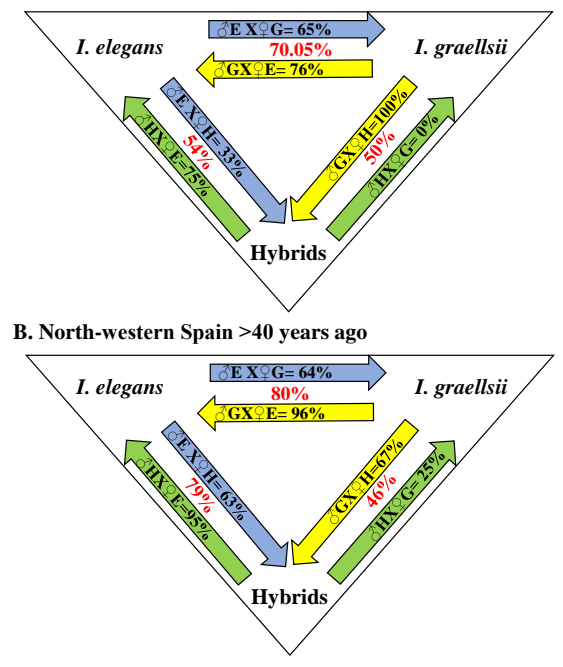

C. North-central Spain $>15$ years ago

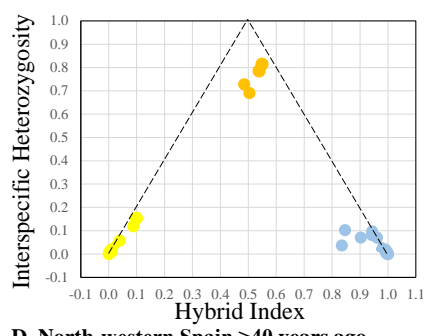

D. North-western Spain $>\mathbf{4 0}$ years ago

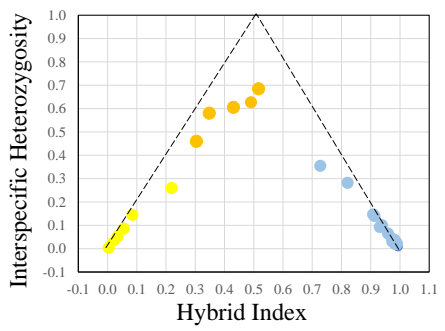



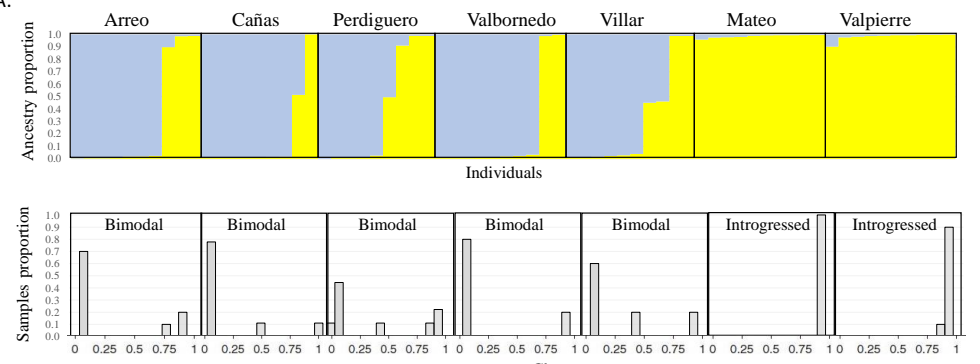

B.
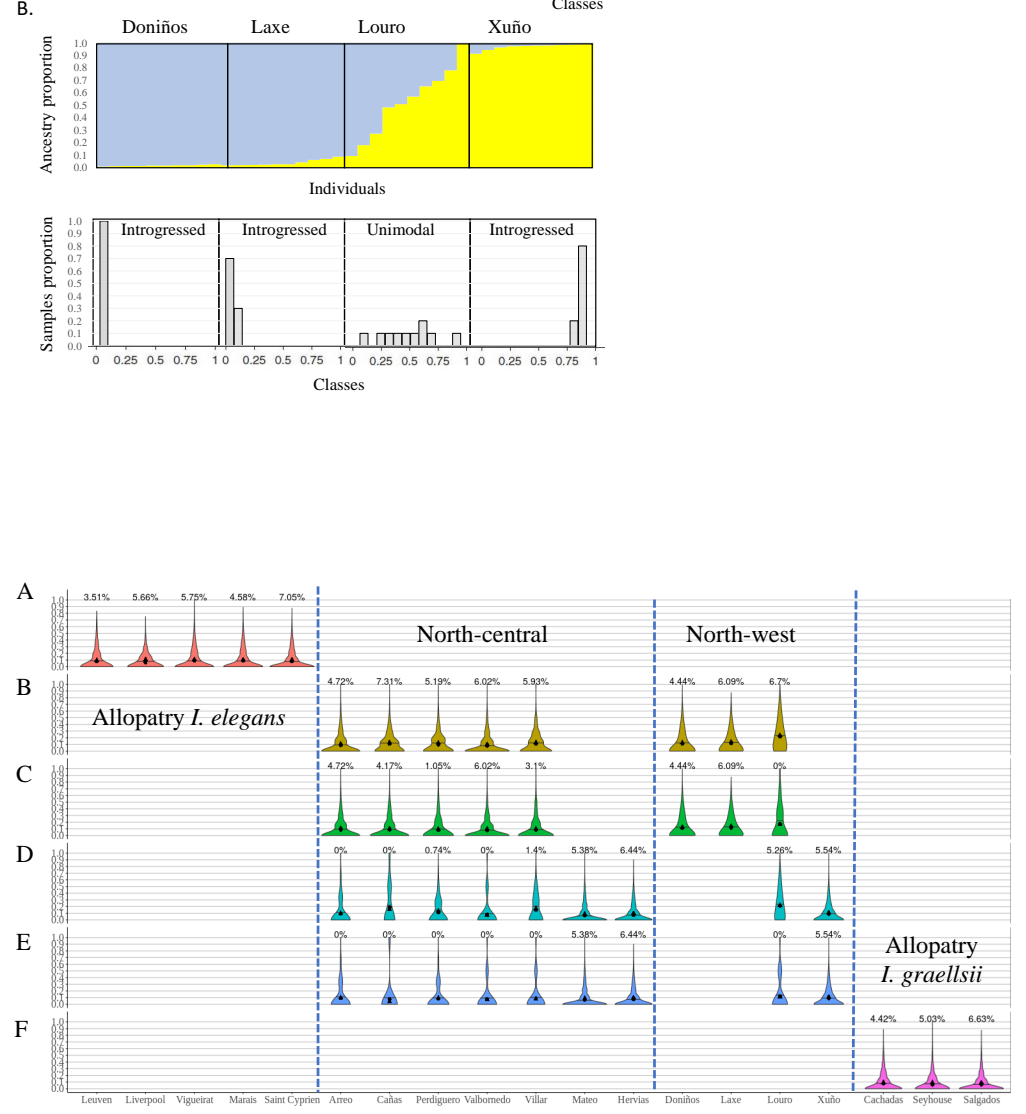